\title{
Complex Treatment of Multiple Sclerosis Patients by Use of Fetal Stem Cells
}

Nataliia Sergiyivna Sych*, Mariya Klunnyk, Iryna Matiyashchuk, Mariya Demchuk, Olena Ivankova, Andriy Sinelnyk, Marina Skalozub Clinical Department, Cell Therapy Center EmCell, Kyiv City, Ukraine

\begin{abstract}
Objective: Refinement for all existing methods of treatment for the multiple sclerosis patients by means of combined method including conventional therapy and administration of fetal stem cells (FSCs)-suspensions containing stem cells derived from human fetal liver and brain.

Materials and methods: 51 patients diagnosed with MS participated in the study including 27 men and 24 women aged 27 to 56 years. Average age range for men was $34.2 \pm 1.2$ years, for women it constituted $31.7 \pm 1.3$ years. 33 patients were allocated in the Main Group (MG) including 20 men (mean age $29.8 \pm 2.2$ years) and 13 women (average age $31.3 \pm 2.1$ years). The Control Group (CG) was composed of 18 patients diagnosed with MSincluding 10 men (mean age of $30.5 \pm 1.2$ years) and 8 women (average age $31.4 \pm 1.4$ years). Simultaneously, the scale of MMSE was applied for objective study of cognitive functions among our patients. State Trait Anxiety Inventory was effective for emotional-anxiety disturbances. In addition, we assessed depression in patients by means of Beck Depression Inventory.

Results: Authors proved efficacy and safety of FSCs suspensions for MS patients. We emphasized a significant improvement of neurology deficit in the MG already over 6 months after fetal stem cells transplantation (FSCT), whereas the CG patients revealed such advantages over 12 months. Improvement of cognitive functions was characteristic for the MG starting from 6 months after FSCT. Anxiety and depression significantly decreased and these results were observed over 6 months after FSCT in the MG. In the CG, the same values which significantly decreased over 12 months after treatment and were recorded.
\end{abstract}

Conclusion: FSCs use in complex treatment of patients with MS stabilizes disease compensation, improves cognitive functions as well as psycho-emotional state of the patients.

Keywords: Cognitive functions; Demyelinating disease; Fetal stem cells; Multiple sclerosis

\section{Abbreviations}

MS: Multiple Sclerosis; CNS: Central Nervous System; RRMS: Relapsing Remitting Multiple Sclerosis; PPMS: Primary Progressive Multiple Sclerosis; APCs: Antigen Presenting Cells; IFN- $\gamma$ : Interferon Gamma; TNFa: Tumor Necrosis Factor a; FSCT: Fetal Stem Cells Transplantation; BBB: Blood Brain Barrier; NO: Nitrogen Oxide; DNA: Deoxyribonucleic Acid; EDSS: Expanded Disability Status Score; MSFC: Multiple Sclerosis Functional Composite; FS: Functional Systems; MG: Main Group; CG: Control Group; FSCs: Fetal Stem Cells; MMSE: Mini Mental State Examination; STAI: State Trait Anxiety Inventory; BDI: Beck Depression Inventory; DMSO: Dimethyl Sulfoxide; IU: International Units; SD: Standard Deviation; TA: Trait Anxiety; SA: State Anxiety; ESCs: Embryonic Stem Cells; EGF: Epidermal Growth Factor; FGF: Fibroblast Growth Factor; BDNF: Brain Derived Neurotrophic Factor.

\section{Introduction}

Multiple Sclerosis (MS) is a chronic inflammatory disease of the Central Nervous System (CNS) ultimately leading to demyelination and axonal loss. This disease is complex and multifactorial, but it seems that the main etiopathogenic event is presented by an aberrant response of the cells of immune system ( $\mathrm{T}$ and $\mathrm{B}$ lymphocytes) to myelin proteins. Three forms of MS disease evolution exist. Approximately $80 \%$ of the patients have a Relapsing Remitting Multiple Sclerosis (RRMS) form; two thirds of them can likely develop a secondary progressive form over 10-15 years starting from MS disease onset. Around 20\% of the patients can develop a progressive form of MS right from very onset, and such a disease is called Primary Progressive Multiple Sclerosis (PPMS) $[1,2]$.
An average age of the patients with MS disease who were studied assembles 30 years. The main peak of morbidity due to MS can be attributed to the age of 20-40 years. Disease onset in the age of patients up to 16 years constitutes about $2.7 \%$ of cases. In addition, MS is rare in the patients who are older than 60 years. Women are commonly suffering from MS disease two times more frequently compared to the men. MS disease incidence could significantly vary among the patients all over the world. Thus, a number of new cases of MS can progressively increase as far distant these patients are from the girdle of the world; in particular, disease prevalence is higher in the regions of North Europe, South Australia and Central part of North America. They believe that around 2 million of MS patients have been registered throughout the world, whereas in Russia this number of patients reaches approximately 150,000 of sufferers $[3,4]$.

Essential success in understanding of MS disease pathogenesis has been recently achieved with establishing contemporary methods of pathogenic treatment for MS. Theory of multifactor etiology of MS is regarded as a generally accepted and it is grounded on interconnection between the factors of external environment (virus and/or another

*Corresponding authors: Nataliia Sergiyivna Sych, Clinical Department Cell Therapy Center EmCell, Kyiv City, Ukraine, Tel: +380688898989; E-mail: lavok114@gmail.com

Received April 19, 2017; Accepted May 02, 2017; Published May 08, 2017

Citation: Sych NS, Klunnyk M, Matiyashchuk I, Demchuk M, Ivankova O, et al. (2017) Complex Treatment of Multiple Sclerosis Patients by Use of Fetal Stem Cells. J Stem Cell Res Ther 7: 386. doi: 10.4172/2157-7633.1000386

Copyright: @ 2017 Sych NS, et al. This is an open-access article distributed unde the terms of the Creative Commons Attribution License, which permits unrestricted use, distribution, and reproduction in any medium, provided the original author and source are credited. 
pathogen as well as geographical regions of residence etc.) and hereditary predisposition to the disease [5].

At the moment such a concept of MS pathogenesis consists in accentuation on initial inflammatory phase of illness and more advanced stage of neurodegeneration in the patients [5-7]. Initiation of immune pathology mechanisms specifically, an activation of anergic, nonreactive CD4+ T cells takes place outside the CNS owing to interaction between a particular T-cell receptor and autoantigen bound to class II molecules within the main histocompatibility complex on dendritic AntigenPresenting Cells (APCs) contributing to T-cells proliferation [6,7].

Reactivation of T-cells by Antigen-Presenting Cells (APCs), in particular, by macrophages and microglial cells takes place in the CNS. Autoreactive T-cells which infiltrate to CNS as well as reactivated macrophages and microglial cells can also secrete anti-inflammatory cytokines (Interferon Gamma (IFN- $\gamma$ ), Tumor Necrosis Factor $\alpha$ (TNFa), Lymphotoxin etc.) that induce and maintain inflammatory reactions to even greater extent and simultaneously enhances disruption of permeability within Blood Brain Barrier (BBB). Activation of immune response with inclusion of macrophages and B-lymphocytes producing antibodies leads to a destruction of the myelin sheath. Phagocytosis of the damaged myelin areas by macrophages is completed with participation of cytotoxic neurotransmitters such as TNFa, active forms of oxygen and metabolites of Nitrogen Oxide (NO) [8].

Immune inflammatory changes and demyelinating lesions are accompanied by neurodegenerative damage with immense number of axons which could be noticed even at early stages of the disease. These are playing an important role in a progression of MS along with occurrence of irreversible invalidity in the patients $[6,8]$. As the most probable factor for a direct destruction of axons in MS we can emphasize expression of class I histocompatibility complex molecule on them making susceptible to CD8+T-lymphocytes cytotoxic influence. Affection of axons might be connected with inflammatory reactions, specifically by elevation of extracellular pressure after edema; excitotoxic damage resulting from effects of excitatory amino acid of glutamate; degenerative changes under influence of nitric oxide. Nevertheless, axonal damage is also possible owing to disruption of trophic maintenance including changes in trophic factors expression as well as chronic demyelinating process by virtue of trophic influence of oligodendrocytes and myelin-axonal interactions $[6,8]$.

Much attention is paid to a balance between destructive and restorative processes at development of neurology deficit in cases of MS [9]. As mechanisms for regression of clinical symptoms we should contemplate decrease of intensity of acute inflammatory reactions, remyelination and better conductivity due to redistribution of sodium channels inside of demyelinated axons. Cognitive disturbances in MS could be manifested from minor disturbances of functions of cognition all the way to dementia development. It is not likely to predict appearance of such disorders, their intensity and dynamics based on the data of clinical manifestations and/or by way of neuroimaging study in a particular patient. It is expected that not only morphological (demyelination and atrophy), but also pre-morphological changes (white and grey matter of the brain macroscopically look normal) are fundamental for cognitive deficit and they have a great clinical significance at the expense of disruption in complex intra and interhemispheric connections responsible for cognitive functions. Consequently, such a well-known phenomenon as brain plasticity which is stipulated by several substrates (including enhanced axonal expression to sodium channels and synaptic changes, recruitment of parallel conductive pathways or latent connections along with reorganization of remote zones like subcortical nuclei being projected onto the brain cortex) having adaptative significance in restriction of functional manifestations in axonal damage by MS disease $[10,11]$.

Above described features can establish a contemporary approach in MS pathogenic therapy which consists in 2 principal directions:

1) Treatment for exacerbations and periods of a sudden growth of disease activity.

2) Prophylaxis of disease exacerbations and progression of invalidity in the patients.

Data of a study of MS disease natural history as well as results of clinical studies proved that the earlier doctors begin adequate therapy for MS patients, the rarer and milder exacerbations of MS disease are.

Subsequently less expressed atrophic processes can persist which may pre-determine stable neurology disorders, disease severity in particular.

Contemporary assessment on effectiveness of methods used for MS treatment is grounded on mandatory application of a range of criteria which make clinical changes in the patients specifically objective and consist in the following 3 directions of therapy:

- Influence on frequency and severity of exacerbations and length of MS disease remission;

- Impact on growth of indices of invalidity according to one of the neurology scales used (Expanded Disability Status Score (EDSS), Multiple Sclerosis Functional Composite (MSFC) etc.);

- Effect on results of Magnetic Resonance Imaging (MRI) which help to estimate both an activity of inflammatory and demyelination processes (total volume of foci, a number of active sites of damage which accumulate paramagnetic contrast), and a character of neurodegenerative changes expressed which might be referred to progression of invalidity (rate of local degeneration-"collapsars" and diffuse atrophies).

The main principle of therapy is administration of treatment by use of glucocorticosteroids which can exert both anti-inflammatory and immune-suppressive action. Supreme efficacy of glucocorticosteroids is gained because of these drugs immediate use in cases with the highest severeness of MS disease exacerbation. Concentration of hormone in the human organism after episodes with MS affection must reach substantially high ranges; therefore, a practice of steroid bursts therapy administration is broadly used (i.v. steroid bursts therapy by use of methylprednisolone in a cumulative dose of 3000-7000 mg). Advantage of i.v. steroid bursts therapy compared to glucocorticosteroids in tablets results in higher effectiveness along with absence of a plenty of side effects specific for a continuous peroral use.

Plasmapheresis could be also used for a relief of severe MS exacerbation (2-3 sessions are needed). High effectiveness of this method is indicated for the patients in combination with intravenous administration of 500-1000 mg methylprednisolone following each manipulation.

Intravenous administration of immunoglobulin $G$ could be alternatively used in some cases for a reduction of marked invalidity and disease prevalence among the patients. Several potential mechanisms of its influence are expected in such patients: binding and activation of pathogenic antibodies to immunoglobulins; block of Fc-receptor on mononuclear phagocytes; modelling of endogenic production of immunoglobulins and relief of the complement-mediated impacts; neutralization of molecules involved into inflammatory reactions; an induction for anti-inflammatory cytokines and a process of apoptosis. However, nowadays we can see a deficit in large controlled clinical studies, restricted value of MRI study data along with a lack of specially 
developed mode of medicines administration as well as high price of medical drugs are regarded as the main problems in application of immunoglobulin in cases of MS.

Nowadays, the main direction in pathogenetic preventive therapy for MS is concentrated on use of drugs which can change a character of MS disease progression (specifically immunomodulatory and immunosuppressive medications).

Immune suppressive agents belong to the first therapy line for MS and contain the following medicines: interferons beta-Betaferon (interferon beta-1b), Rebif (interferon beta-1a) for subcutaneous use and Avonex (interferon beta-1a) for intramuscular injections along with glatiramer acetate (Copaxone ${ }^{\oplus}$-Teva).

All 3 interferon-based medicines are being produced by means of gene-engineering methods using a recombinant DNA. Copaxone ${ }^{\otimes}-\mathrm{Teva}$ is a synthetic analogue of one of immune modulatory zones in human myelin layer. All three interferon beta medicines are indicated for treatment of relapsing remitting MS.

Drugs of the 2nd therapy line which can affect MS disease progression are regarded as medicines with immunosuppressive action: natalizumab (Tysabri); nonselective agents-Mitoxantrone (Novantrone), Alemtuzumab; selective medicines-rituximab, cladribine etc. Such agents are recommended in cases with significant aggravation among the patients suffering from relapsing-remitting and secondary progressive MS diseases, provided interferon beta and glatiramer acetate are non-effective in the patients. Upon administration such medicines very often lead to the influenza-like symptoms and this makes their use in all patients with MS disease problematic. For this reason, a search for up-to-date and contemporary methods of treatment for MS was initiated by the researchers all over the world. Specifically, stem cell therapy can be regarded as one of such therapy modes.

One of the key questions regarding stem cell therapy is cell fate determination and lineage commitment of the pluripotent exogenous stem cells. Emerging evidences indicate that epigenetic mechanisms play an essential role in this process. For instance, blocking the catalytic activity of histone H3K9 methyltransferase G9a is able to convert bone marrow derived Mesenchymal Stem Cells (MSCs) to cardiac progenitors [12]. This observation suggests that for the patients with cardiac disorders application of MSCs that pre-treated with G9a inhibitors might increase the efficacy of the therapy. Interestingly, since G9a also regulates the Polycomb Repressive Complex 2 (PRC2) associated gene silencing [13] and maintains DNA methylation in ES cells [14], investigation on the chromatin loading patterns of G9a in pluripotent and differentiated ES cells might lead us to better understand the mechanisms required for committed differentiation of stem cells and refine the regimen of stem cell therapy.

Researchers proved efficacy of non-myeloablative hematopoietic stem cell transplantation which was associated with improvement of neurological disability and the other clinical outcomes among the patients with relapsing remitting MS [15].

The aim of this study was to evaluate a dynamics of cognitive and emotional disorders in patients suffering from MS during the course with complex therapy using FSCs isolated from human fetuses of 7-12 weeks gestation.

Our main objective was improving methods of treatment for the patients with MS by means of a combination with inclusion of conventional therapy (medicines, physiotherapy) and administration of FSCs suspensions containing embryonic stem cells separated from fetal

\section{liver and brain.}

\section{Materials and Methods}

This study involved 51 patients diagnosed with MS in the age of 27 to 56 years including 27 men with average age $34.2 \pm 1.2$ years and 24 women, whose mean age was $31.7 \pm 1.3$ years respectively. Diagnosis of MS disease had been established for all patients based on McDonald diagnostic criteria (2010) [6]. For evaluation of expressed neurology deficit and state of functional conductivity of systems doctors applied the Kurtzke scale: a method used to evaluate the state of Functional Systems (FS) along with EDSS [16].

Initially all patients were split into the Main Group (MG) which included 33 MS patients (20 were men with their mean age of $29.8 \pm$ 2.2 years); at the same time, 13 women were under study and their average age constituted $31.3 \pm 2.1$ years. 18 patients with MS disease were allocated in the Control Group (CG) including 10 men with their mean age range of $30.5 \pm 1.2$ years and 8 women whose mean age made up $31.4 \pm 1.4$ years.

All treated patients followed their pathogenetic therapy containing the following medicines and regimens: doctors prescribed Betaferon in a dose of $250 \mathrm{mcg}$ ( $8 \mathrm{IU}$ ) administered subcutaneously (s.c.) each another day (for 17 patients under study), Rebif $44 \mathrm{mg}$ by s.c. use t.i.d. (undertaken by 12 patients) and Avonex, which was used for intramuscular (i.m.) injections once per week in a dose of $20 \mathrm{mg}$ prescribed for 11 patients in the study group. On the base of classical therapy MS patients were transplanted FSCs received from embryonic human fetuses of 7-12 weeks gestation. Abortive material was tested by means of microbiology and virology studies. For a purpose of safety, both women donors and readily made fetal stem cells were tested for parasites, mycotic, bacterial and viral infections such as toxoplasmosis (Toxoplasma gondii), rubella, cytomegalovirus, herpes simplex virus 1 and 2, Epstein-Barr virus, human immunodeficiency virus 1 and 2, hepatitis B virus, hepatitis C virus, syphilis (Treponema pallidum), Ureaplasma urealyticum, Ureaplasma parvum, Mycoplasma genitalium and Chlamydia trachomatis.

In order to objectively assess cognitive functions Mini Mental State Examination (MMSE) [17] was used, which could facilitate evaluation of quick and effective orientation in time and space; rates of perception and concentration; state of short-time and long-time memory the same as speech functions, acoustic gnosis and praxis. By means of a set of tests by Isaac on speech activity we determined ability to recall the listed words according to 4 semantic categories.

State Trait Anxiety Inventory (STAI) testing by Spielberger anxiety scale was applied to define emotional anxiety breakdown among the patients. Such an evaluation is considered to be the most effective and can contribute to assessment of state anxiety which is a state of the patient at this moment as well as trait anxiety being a stable characteristic in a human [18]. Test results have been evaluated in the following way: up to 30 scores-low anxiety, 31-45 scores-moderate anxiety, and over 46 scores - high anxiety. Beck Depression Inventory (BDI) scale was used for assessment of depression in the patients [19].

Analysis of all indices was made before treatment, over 6 and 12 months after FSCs therapy. Study was conducted in accordance with good clinical practice, Helsinki declaration and in conformity with the ethical standards for work with human embryonic tissues approved by the Ministry of Health of Ukraine. Our study was also approved by the local ethics committee established on the base of Kyiv City Clinical Emergency Hospital and located on the address: 3 Bratyslavska str., Kyiv 
City, Ukraine.

\section{Stem cells procedure}

Biotechnology process of suspension preparing suggested stem cells extraction from different growth zones of human fetus (embryonic liver, brain, heart and soft tissues); assessment of viability of cells and their programmed cryopreservation; testing for viral and bacterial infections. Received suspension containing stem cells of fetal liver with cell activity products was placed into the polyethylene sterile test tubes in a volume of $0.3-1.8 \mathrm{~mL}$.

Cryopreservation using $5 \%$ dimethyl sulfoxide (DMSO) as cryoprotectant was performed in a controlled-rate freezer chamber pursuant to the selected program and at the initially adjusted temperature of $1{ }^{\circ} \mathrm{C} / \mathrm{min}$ for crystals forming initiation.

Defrost of cryopreserved suspension is made on a water bath for thawing at temperature of $37.5^{\circ} \mathrm{C}$.

Immediately before administration doctors perform calculation of cells viability: count of nucleated stem cells.

Total count of nucleated cells is calculated per volumetric unit by means of cells analyzer (Automated Cell Counter NC-100; Nucleo Counter Type 900-004 Chemo Metec, Denmark 2010) or visually under the microscope using a counting cell chamber. Cells viability after freezing made up $90 \%$ in the least. Administration of stem cell suspension was performed during 2 days: day 1 use of a suspension containing fetal liver cells in the volume of $3.2 \pm 0.74 \mathrm{~mL}$, including $34.13 \pm 0.52 \times 10^{6}$ of nucleated cells and cell precursors of CD34+ which ranged from 0.3 to $3.15 \times 10^{6} / \mathrm{mL}$ per one injection; by means of $200 \mathrm{~mL}$ drip-feed intravenous infusion diluted by $0.9 \%$ physiological solution. On day 2, we injected suspensions prepared from fetal brain tissue into the anterior abdominal wall in the volume of $4.18 \pm 1.02$ $\mathrm{mL}$. The amount of vital cells in the suspension corresponded to 70.0 $\pm 10.0 \%$.

\section{Statistics}

Statistical analysis of the data was performed by Statistica v.8.0 (StatSoft, Inc., Tulsa, OK, USA), including calculation of mean and Standard Deviation (SD). Bonferroni multiple comparison correction test and Student's t-test (parametric statistics) were used to determine significance of the results ( $<<0.05$ was regarded as significant).

\section{Results}

All patients under study revealed a syndrome of early post-infusion effects: they reported improved sleep, better appetite and mood; reduced muscle tone was also characteristic for the patients. No single case of complication or side effect was recorded among the patients following injections of cryopreserved suspensions with fetal liver stem cells, in the meantime, the patients under study did not report "graftversus-host disease".

The patients revealed post-transplantation results which were associated with significant improvement by EDSS scores (Table 1). The EDSS score improved significantly in the MG patients $(\mathrm{P}<0.001$ at all-time intervals except for 1 year). In this respect, over 6 months after treatment in patients of the MG one can observe a decrease by $\geq 1.0$ point (improvement) in 18 individuals whereas over 1 year such an improvement was recorded in 24 patients under study, $(<0.001)$. Increase or decrease by $\leq 0.5$ point in 8 patients of the MG over 6 months and among 6 patients of the MG for a period of observation over 12 months after FSCT were also characteristic. Increase by $\geq 1.0$ point (progression) was remarkable for 7 patients of the MG over 6 months after therapy as well as for 3 patients in the MG over 1 year after FSCT. Simultaneously, among the CG patients we recorded a significant decrease of the scores by EDSS scale over 1 year after treatment (mean score was 4.5 (2.5) before treatment and 2.9 (2.2) over 12 months after therapy, $\mathrm{p}<0.001$ ). Decrease by $\geq 1.0$ point (improvement) was remarkable for 5 patients of the CG over 6 months and for 9 patients over 1 year after conventional treatment. Increase or decrease by $\leq$ 0.5 point can be observed in 2 patients of the CG over 6 months after treatment, whereas in 4 patients it was recorded over 12 months after treatment. Increase by $\geq 1.0$ point (progression) was identified in $11 \mathrm{CG}$ patients over 6 months after treatment and in 5 patients this result was recorded over 12 months.

Baseline level of cognitive function by MMSE scale was identified as follows: for the patients of the MG this level made up $23.89 \pm 0.51$ scores, whereas for the patients in the CG the same value constituted $23.43 \pm 0.59$ scores. Such data are cited in Figure 1. As a result of treatment over 6 months we could establish a significant improvement in cognitive state of the MG patients $-25.74 \pm 0.42$ scores as compared to the CG patients-23.78 \pm 0.91 scores, $(\mathrm{p}>0.05)$. Over 1 year after treatment using FSCs a significant increase in the mean score by MMSE scale was observed in patients of the MG-26.95 \pm 0.30 scores and the same increase in the mean score was remarkable for the CG patients: $23.79 \pm 0.55$ scores, but this value was not regarded as significant for this group of patients under study $(\mathrm{p}>0.05)$.

With the help of a set of tests by Isaac on speech activity patient's ability to recall the listed words according to 4 semantic categories has been assessed. Mean score in the patients of the MG composed $31.9 \pm$

\begin{tabular}{|c|c|c|c|c|c|c|}
\hline \multirow[b]{2}{*}{ EDSS Score } & \multicolumn{3}{|c|}{ MG } & \multicolumn{3}{|c|}{ CG } \\
\hline & Before FSCT & Over 6 months & Over 1 Year & Before Treatment & Over 6 months & Over 1 Year \\
\hline Median (IQR) & $4.0(3.0-5.5)$ & $3.0(2.0-3.5)$ & $3.0(1.5-3.5)$ & $4.0(3.0-5.5)$ & $3.5(2.5-3.5)$ & $3.0(2.5-3.5)$ \\
\hline Mean (SD) & $4.1(1.5)$ & $3.1(1.6)$ & $2.8(1.5)$ & $4.5(2.5)$ & $3.8(2.6)$ & $2.9(2.2)$ \\
\hline $95 \% \mathrm{Cl}$ & $3.96-5.24$ & $2.99-3.50$ & $2.76-3.41$ & $3.96-5.44$ & $3.2-3.50$ & $2.96-3.44$ \\
\hline$P$ value $^{2}$ & & $<0.001$ & $<0.001$ & & & $<0.001$ \\
\hline Decrease by $\geq 1.0$ point (improvement) & & 18 & 24 & & 5 & 9 \\
\hline Increase or Decrease by $\leq 0.5$ point & & 8 & 6 & & 2 & 4 \\
\hline Increase by $\geq 1.0$ point (progression) & & 7 & 3 & & 11 & 5 \\
\hline
\end{tabular}

IQR: Interquartile Range; SD: Standard Deviation; Cl: Confidence Interval; MG: Main Group; CG: Control Group.

1. The range of scores is 0 to 10 in 0.5 increments.

2. Comparison group is before FSCT.

Table 1: Association of Fetal Cell Transplantation (FSCT) and changes in scores by Expanded Disability Status Scale (EDSS) in the patients of MG and CG. 
1.2 out of 40 scores possible, whereas among the patients of the CG this mean value was $30.2 \pm 1.3$. All patients in this group revealed a tendency to repetition of the same words within the semantic category. Over 6 months after treatment this parameter enhanced and it constituted $37.2 \pm 2.1$ for the patients in the MG ( $\mathrm{p}<0.05)$, simultaneously, among the patients of the CG this value made up $34.7 \pm 2.2(\mathrm{p}>0.05)$. Over 1 year after treatment the same result was significantly higher among the patients of both groups by $39.1 \pm 1.5$ and by $38.7 \pm 2.2$ respectively. In addition, the patients stopped repetition of the identical words from the semantic list.

Having analyzed the results obtained by the test of STAI for the rate of anxiety in the patients after complex treatment the following data were recorded (Figure 2).

Over 6 months after treatment in patients of the Main Group the level of Trait Anxiety (TA) significantly decreased over $8.16 \%(\mathrm{p}<0.05)$; at the same time, over 12 months the level of TA was significantly reduced by $9.18 \%$; however, in patients of the CG the same parameter significantly decreased by $6.60 \%$ over 12 months after treatment. State anxiety (SA) index significantly decreased by $7.51 \%$ in the patients of the MG over 12 months compared to the results baseline, $\mathrm{p}<0.05$.

We identified depression in the patients under study by use of Beck Depression Inventory (BDI) scale both in the MG and CG (Figure 3).

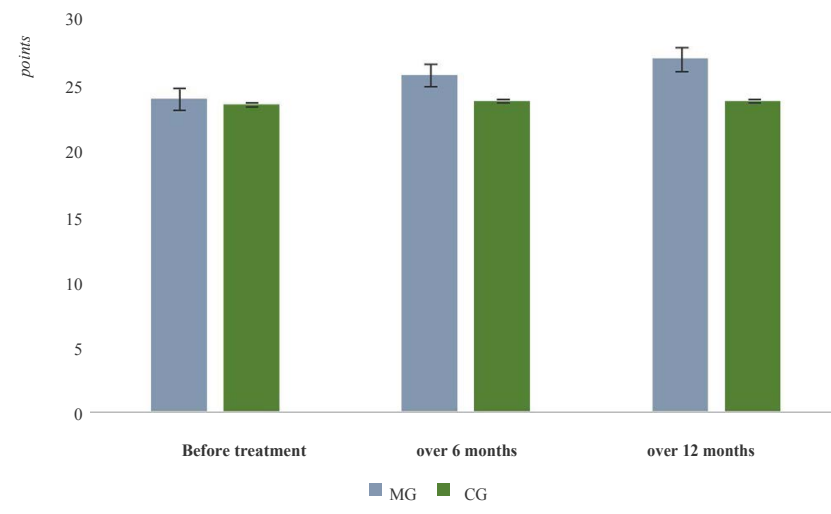

${ }^{*} \mathrm{p}<0.05$ between baseline and the results over 6 months after FSCT; ${ }^{* *} \mathrm{p}<0.05$ between baseline and the results over 12 months after FSCT

Figure 1: Dynamics of cognitive functions according to MMSE scale in patients of the MG and CG.

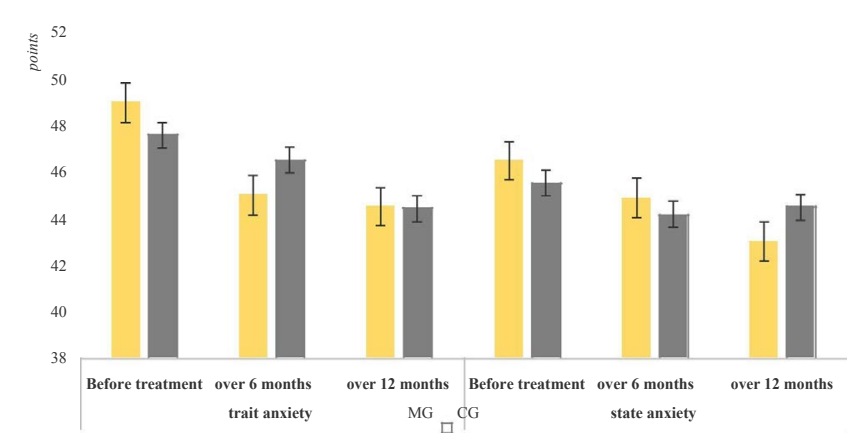

${ }^{*} \mathrm{p}<0.05$ between baseline and the results over 6 months after FSCT; ** $\mathrm{p}<0.05$ between baseline and the results over 12 months after FSCT

Figure 2: Dynamics of cognitive functions according to MMSE scale in patients of the MG and CG.

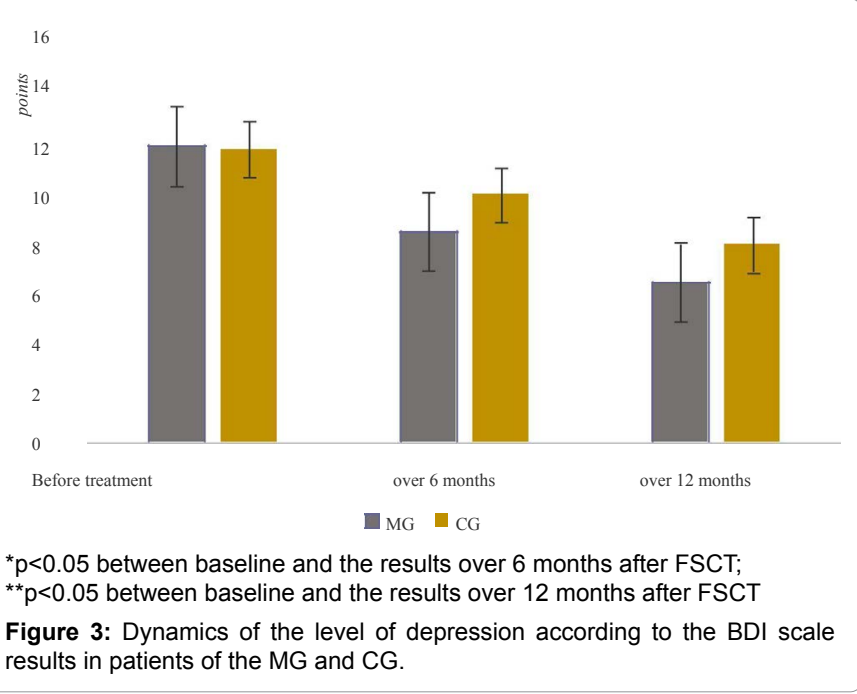

Over 6 months after treatment, reduction of depressive state was observed in the MG patients according to the results by BDI scale (up to $8.57 \pm 0.06$ scores; over $22.10 \%$ from the results baseline), $\mathrm{p}<0.05$., whereas over 12 months after treatment, a relief of depressive state among the patients remained significant both for the MG and CG.

\section{Discussion}

Principal and common mechanisms of stem cells effect include induction of neuro-regeneration and remyelination through activation of resident stem cells; specifically by production of the new progenitors from CNS cell lineage, paralleled by local and systemic immunomodulation effects.

Embryonic Stem Cells (ESCs) derived from the inner cell mast of the blastocyst are capable of giving rise to cells of all three germ layers. ESCs have been proven to differentiate in vitro into several cell types of the body including neuronal stem cells. Actual fate of such a differentiation is determined by the growth factors, chemical agents and neurotrophic factors, for instance, Epidermal Growth Factor (EGF), Fibroblast Growth Factor (FGF), Brain-Derived Neurotrophic Factor (BDNF) and retinoic acid [20-23]. Differentiation of pluripotent embryonic stem cells from the neuronal lineage in vitro gives rise to mature inhibitory and excitatory neurons [22-24]. ESCs express distinct surface markers, such as Oct-4, Sox-2 and SSEA-1/2/3/4. Several studies identified an ability of such cells to differentiate into myelin-producing cells (oligodendrocytes) [25-33] and neurons [3436] therefore, became suitable candidates for neuro-regeneration and remyelination in diseases such as MS. In a recent study it was established that neurospheres derived from ESCs being obtained from ILRIL6 chimeras (soluble IL-6 receptor fused to IL-6) and could exhibit higher differentiation into oligodendrocytes with more branches and peripheral accumulation of myelin-basic protein on myelin membranes [36]. Transplantation of differentiated oligodendroglial progenitors derived from ESCs to the shiverer mouse model of demyelination resulted in integration, differentiation into oligodendrocytes and compact myelin formation [28]. When transplanted to rodent models with induced demyelination, ESCs were able to differentiate into glial cells and re-ensheath demyelinated axons in vivo [31,32].

In summary, use of stem cells may open a new era in management 
Citation: Sych NS, Klunnyk M, Matiyashchuk I, Demchuk M, Ivankova O, et al. (2017) Complex Treatment of Multiple Sclerosis Patients by Use of Fetal Stem Cells. J Stem Cell Res Ther 7: 386. doi: 10.4172/2157-7633.1000386

Page 6 of 7

of MS disease, as well as the other neurodegenerative and neuroimmunology disorders. In MS, a potential of stem cells to migrate into the affected inflammatory CNS sites seems to be the key element for their possible efficacy by favorable inducing local immunomodulation (which is usually inefficient by the other means, i.e., via systemic administration of immunomodulating drugs) and neuroprotection; accelerating and enhancing the remyelinating mechanisms through induction of the growth factors or activation of the resident stem cell repertoire. Possibility of transdifferentiation into myelin-producing cells or neurons theoretically exists and this could be supported by several lines of evidence which prove that transplanted cells can express the markers of neurons and oligodendrocytes on animal models. The others have suggested that fusion mechanisms may be involved, but not real trans-differentiation. If this is the case, then fusion mechanisms might also be of advantage, which promote rejuvenation of the partially damaged CNS cells.

\section{Conclusion}

In MS patients, FSCT results in inhibition of the disease progression and improvements of different manner, such as:

1. Authors proved efficacy and safety of treatment by use of FSCs in the patients with MS.

2. Statistically significant improvement in neurology deficit among the patients of the MG has already been observed over 6 months after treatment; simultaneously, the patients of the CG reported improvements over 12 months after conventional treatment for MS.

3. Improvement of cognitive function was characteristic for MS patients of the MG starting from a period of observation over 6 months after FSCT.

4. Significant reduction of the levels of anxiety and depression over 6 months after FSCs therapy was recorded in the MG patients. Among the patients of the CG, such values were significantly lower over 12 months after MS treatment.

In order to inhibit fast progression of MS and improve a quality of activities of daily living among the patients, FSCT along with physiotherapy and massage are proved to be especially effective.

In fact, one must understand that a small number of patients participated in this study. In addition, such improvements can only appear for a definite period of time. Therefore, further studies with randomized and placebo-controlled trials might be demanded to promote an evidence of long-term effectiveness and improvement of overall health among the MS patients after complex therapy using FSCT.

\section{Conflict of Interest}

The authors of the above study reported no conflict of interest at the moment of this article submission for publication within this journal.

\section{References}

1. Cohen JA, Rudrick RA (2007) Aspects of multiple sclerosis that relate to trial design and clinical management. In: Cohen JA, Rudrick RA, eds. Multiple Sclerosis Therapeutics. Boca Raton, FL: Taylor \& Francis, pp: 3-23.

2. Gusyev El, Zavalishin IA, Boyko AN (2004) Multiple sclerosis and the other demyelinating diseases. Miklosh, Moscow p: 540.

3. Kobelt G, Berg J, Atherly D, Michael OH (2006) Costs and quality of life in multiple sclerosis: a cross-sectional study in the United States. Neurology 66: 1696-1702. [PubMed]

4. Kobelt G, Berg J, Lindgren P, Fredrikson S, Jönsson B (2006) Costs and quality of life of patients with multiple sclerosis in Europe. J Neurol Neurosurg Psychiatry 77: 918-926. [PubMed]

5. Ciess R, Maurer M, Linker R (2002) A null mutation in the CNTF gene is associated with early onset of multiple sclerosis. Arch Neurol 59: 407-409. [PubMed]

6. Kulakova OG (2004) Role of cytokines in immune-pathogenesis of multiple sclerosis. Guidance for the doctors: Multiple sclerosis and the other demyelinating diseases. In: Boyko OG, Favorova OO Eds. pp: 75-92.

7. Magayeva S, Morozov SG (2005) Immune regulation of functions of CNS Neuroimmunophysiology, SI NRI of biomedical chemistry after V.N. Orekhovich RAMS, Moscow, pp: 44-86.

8. Nikiforova IG (2003) Particularities of interrelation between neuroimmunology abnormalities and demyelinating lesions at multiple sclerosis: Extended abstract of Cand SciThesis. St. Petersburg, pp: 22

9. Nikiforova IG, Ilves AG, Votintseva MV (2003) Immunology studies in diagnostics of multiple sclerosis. Neurology 8: 9-14.

10. Schmidt TE, Yakhno NN (2010) Multiple sclerosis: guidance for the doctors. MEDpress-inform, pp: 272.

11. Bjartmar C, Wujek JR, Trapp BD (2003) Axonal loss in pathology of MS consequences for understanding the progressive of the disease. J Neurol Sci 206: 165-171. [PubMed]

12. Yang J, Kaur K, Ong LL, Eisenberg CA, Eisenberg LM (2015) Inhibition of G9a histone methyltransferase converts bone marrow mesenchymal stem cells to cardiac competent progenitors. Stem Cells Int 2015: 270428. [PubMed]

13. Mozzetta C, Pontis J, Fritsch L, Robin P, Portoso M, et al. (2014) The histone H3 lysine 9 methyltransferases G9a and GLP regulate polycomb repressive complex 2-mediated gene silencing. Mol Cell 53: 277-289. [PubMed]

14. Zhang T, Termanis A, Ozkan B, Bao XX, Culley J, et al. (2016) G9a/GLP Complex Maintains Imprinted DNA Methylation in Embryonic Stem Cells. Cell Rep 15: 77-85. [PubMed]

15. Burt RK, Balabanov R, Han X, Sharrack B, Morgan A, et al. (2015) Association of Nonmyeloablative Hematopoietic Stem Cell Transplantation With Neurological Disability in Patients With Relapsing-Remitting Multiple Sclerosis. JAMA 313: 275-284. [PubMed]

16. Kurtzke JF (1983) Rating neurologic impairment in multiple sclerosis: an expanded disability status scale (EDSS). Neurology 33: 1444-1452. [PubMed]

17. Pangman VC, Sloan J, Guse L (2000). "An Examination of Psychometric Properties of the Mini-Mental Status Examination and the Standardized MiniMental Status Examination: Implications for Clinical Practice". Appl Nurs Res 13: $209-213$

18. Spielberger CD, Gorsuch RL, Lushene R, Vagg PR, Jacobs GA (1970) Manual for the State-Trait Anxiety Inventory. CA: Consulting Psychologists Press, Palo Alto.

19. Beck AT, Ward Ch, Mendelson M, Mock J, Erbaugh J, et al. (1961) An Inventory for Measuring Depression. Arch Gen Psychiatry 4: 561-571. [PubMed]

20. Bain G, Kitchens D, Yao M, Huettner JE, Gottlieb DI (1995) Embryonic stem cells express neuronal properties in vitro. Dev Biol 168: 342-357. [PubMed]

21. Strubing C, Ahnert-Hilger G, Shan J, Wiedenmann B, Hescheler J, et al. (1995) Differentiation of pluripotent embryonic stem cells into the neuronal lineage in vitro gives rise to mature inhibitory and excitatory neurons. Mech Dev 53: 275 287. [PubMed]

22. Fraichard A, Chassande O, Bilbaut G, Dehay C, Savatier P, et al. (1995) In vitro differentiation of embryonic stem cells into glial cells and functional neurons. $J$ Cell Sci 108: 3181-3188. [PubMed]

23. Reubinoff BE, Itsykson P, Turetsky T, Pera MF, Reinhartz E, et al. Neural progenitors from human embryonic stem cells. Nat Biotechnol 19: 1134-1140. [PubMed]

24. Benzing C, Segschneider M, Leinhaas A, Itskovitz-Eldor J, Brustle O (2006) Neural conversion of human embryonic stem cell colonies in the presence of fibroblast growth factor-2. Neuroreport 17: 1675-1681. [PubMed] 
Citation: Sych NS, Klunnyk M, Matiyashchuk I, Demchuk M, Ivankova O, et al. (2017) Complex Treatment of Multiple Sclerosis Patients by Use of Fetal Stem Cells. J Stem Cell Res Ther 7: 386. doi: 10.4172/2157-7633.1000386

25. Kang SM, Cho MS, Seo H, Yoon CJ, Oh SK, et al. (2007) Efficient induction of oligodendrocytes from human embryonic stem cells. Stem Cells 25: 419-424. [PubMed]

26. Billon N, Jolicoeur C, Raff M (2006) Generation and characterization of oligodendrocytes from lineage-selectable embryonic stem cells in vitro. Methods Mol Biol 330: 15-32. [PubMed]

27. Mueller D, Shamblott MJ, Fox HE, Gearhart JD, Martin LJ (2005) Transplanted human embryonic germ cell-derived neural stem cells replace neurons and oligodendrocytes in the forebrain of neonatal mice with excitotoxic brain damage. J Neurosci Res 82: 592-608. [PubMed]

28. Nistor GI, Totoiu MO, Haque N, Carpenter MK, Keirstead HS (2005) Human embryonic stem cells differentiate into oligodendrocytes in high purity and myelinate after spinal cord transplantation. Glia 49: 385-396. [PubMed]

29. Liu S, Qu Y, Stewart TJ, Howard MJ, Chakrabortty S, et al. (2000) Embryonic stem cells differentiate into oligodendrocytes and myelinate in culture and after spinal cord transplantation. Proc Natl Acad Sci USA 97: 6126-6131. [PubMed]

30. Srivastava AS, Shenouda S, Mishra R, Carrier E (2006) Transplanted embryonic stem cells successfully survive, proliferate, and migrate to damaged regions of the mouse brain. Stem Cells 24: 1689-1694.
31. McDonald JW, Liu XZ, Qu Y, Liu S, Mickey SK, et al. (1999) Transplanted embryonic stem cells survive, differentiate and promote recovery in injured rat spinal cord. Nat Med 5: 1410-1412. [PubMed]

32. Brustle O, Jones KN, Learish RD, Karram K, Choudhary K, et al. (1999) Embryonic stem cell-derived glial precursors: a source of myelinating transplants. Science 285: 754-756. [PubMed]

33. Zeng L, Rahrmann E, Hu Q, Lund T, Sandquist L, et al. Multipotent adult progenitor cells from swine bone marrow. Stem Cells 24: 2355-2366. [PubMed]

34. Zhang SC, Wernig M, Duncan ID, Brustle O, Thomson JA (2001) In vitro differentiation of transplantable neural precursors from human embryonic stem cells. Nat Biotechnol 19: 1129-1133. [PubMed]

35. Reubinoff BE, Itsykson $P$, Turetsky T, Martin FP, Reinhartz E, et al. (2001) Neural progenitors from human embryonic stem cells. Nat Biotechnol 19: 11341140 .

36. Zhang PL, Izrael M, Ainbinder E, Ben-Simchon L, Chebath J, et al. (2006) Increased myelinating capacity of embryonic stem cell derived oligodendrocyte precursors after treatment by interleukin-6/soluble interleukin-6 receptor fusion protein. Mol Cell Neurosci 31: 387-398. [PubMed] 